\title{
Motility of the jejunum after proctocolectomy and ileal pouch anastomosis
}

\author{
S CHAUSSADE, F MERITE, M HAUTEFEUILle, P VAllEUR, \\ $P$ HAUTEFEUILLE, AND D COUTURIER
}

From the Service de Gastroenterologie, Hopital Cochin, Paris, France, and Service de Chirurgie Digestive, Hopital Lariboisiere, Paris, France

Summary Proctocolectomy with ileal pouch anastomosis could modify motility of the small intestine through two mechanisms: obstruction or bacterial overgrowth. Motility of the jejunum was measured in 11 patients with ileoanal anastomosis six $(n=6)$, or $12(n=5)$ months after closure of the loop ileostomy. Manometric recording from the jejunum were made during fasting (four hours) and after a liquid meal (one hour). These findings were compared with those of six healthy volunteers. Motor events were classified as follows: migrating motor complex (MMC), propagated contractions, or discrete clustered contractions. All patients were investigated for bacterial overgrowth (D-glucose breath test). Only two patients had bacterial overgrowth. The frequency of MMC remained unchanged after ileo-anal anastomosis $(2 \cdot 83(0 \cdot 37)$ /four hours) compared with normal volunteers $(2 \cdot 81(0 \cdot 29)$ /four hours). During fasting, four patients had numerous propagated contractions in the jejunum. This condition was associated in two with bacterial overgrowth and in two with intubation of the reservoir. Discrete clustered contractions were found in the seven patients studied postprandially $(7.6(2 \cdot 5) / \mathrm{h})$, but not in volunteers. These seven patients emptied their pouch spontaneously and bacterial overgrowth was found in only one. As this motility pattern was previously described in partial small intestinal obstruction, it is postulated that discrete clustered contractions could be the consequence of a functional obstruction as a result of anastomosis of the small intestine to the high pressure zone of the anal sphincters.

Proctocolectomy with ileal pouch anastomosis is used in chronic ulcerative colitis or familial polyposis.' This procedure avoids a permanent ileostomy and combines the advantages of diseased mucosa extirpation and of continence conservation. Some patients, however, complain of excessive stool frequency, soiling, diarrhoea, and urgency, which are possibly related to modifications of small intestinal motility. In theory, ileal pouch anastomosis could modify

\footnotetext{
Address for correspondence: Dr S Chaussade, Service d'Hepato-GastroEnterologie, Hopital Cochin, Pavillon Brissaud, 27 rue du Faubourg SaintJacques, Paris, 75014, France.

Accepted for publication 1 September 1988.
}

motility of the small intestine through two mechanisms: obstruction and bacterial overgrowth.

Intestinal obstruction is likely as the anal sphincter is closed at most time. ${ }^{23}$ Moreover some patients must catheterise their ileal pouch to evacuate. ${ }^{4}$ In addition fasted and fed jejunal motor patterns have been described for patients with partial small bowel obstruction. 5

Bacterial overgrowth in the pouch is a constant feature. ${ }^{6}$ Thus it is tempting to assume that jejunal bacterial overgrowth develops in the jejunum after ileal pouch anastomosis and modifies small bowel motility.

The aims of the study were (1) to record jejunal motility in patients with ileoanal anastomosis and to 
compare their patterns with those of healthy volunteers and (2) to identify specific motor patterns suggestive of partial obstruction and to correlate motility patterns with the occurrence of bacterial overgrowth in the proximal jejunum.

\section{Methods}

PATIENTS

Eleven patients (six men, five women; mean age, 36 years; range 31-73) who had undergone proctocolectomy with ileal anastomosis for chronic ulcerative colitis $(n=10)$ or familial polyposis $(n=1)$ were recruited for study. The surgical procedure consisted of proctocolectomy, and ileal pouch anastomosis without conservation of a rectal muscular cuff. ${ }^{2}$ Four patients had a $S$ shaped reservoir and seven patients had a $\mathbf{J}$ shaped reservoir. A temporary loop ileostomy was done in all cases. Studies were conducted six months $(n=6)$ or 12 months $(n=5)$ after closure of the ileostomy and restoration of intestinal continuity. All medication was withheld 48 hours before the study.

All the patients had a saline continence test ${ }^{7}$ to assess the quality of the continence and defecation. A polyvinyl probe was inserted (od=7 $\mathrm{mm}$ ) into the ileal reservoir until its tip was approximately about $9 \mathrm{~cm}$ from the anal margin. While subjects sat on a portable commode with a special volumetric collection vessel, $150 \mathrm{mM} \mathrm{NaCl}$ were infused at $60 \mathrm{ml} / \mathrm{min}$ during 25 minutes. The saline continence test was interrupted when the first leakage $(>10 \mathrm{ml})$ appeared or when the subjects complained of a sustained feeling of nausea or pelvic discomfort or when the $1500 \mathrm{ml}$ were infused. At the end of the saline continence test, the patients were asked to evacuate the pouch contents as completely as possible for five minutes. The evacuated volume of saline was measured and the efficiency of pouch evacuation was represented by the ratio of the evacuated volume divided by the maximum tolerable volume retained during the saline continence test.

Six healthy volunteers served as controls. None had any previous intestinal operation or gastrointestinal disease; they had a mean age of 28 years (range 20-42). Patients and controls gave written informed consent.

MOTILITY RECORDING

Intraluminal pressures were recorded with a 4 lumen probe made up of four channels (id $1 \mathrm{~mm}$ ) and an additional radio-opaque channel attached to a latex balloon at the tip of the probe. The radio-opaque channel allowed inflation of a terminal balloon which assisted passage through the bowel. The four sideholes were located at $0,30,60$, and $90 \mathrm{~cm}$ from the tip
Table 1 Effect of ileal pouch anastomosis on the migrating motor complex (values are mean (SEM)

\begin{tabular}{|c|c|c|c|c|}
\hline & Sex & $\begin{array}{l}\text { Phase } 3 / 4 h \\
(n)\end{array}$ & $\begin{array}{l}\text { Duration of } \\
\text { phase } 3 \\
\text { (min) }\end{array}$ & $\begin{array}{l}\text { Velocity of } \\
\text { phase. } 3 \\
(\mathrm{~cm} / \mathrm{min})\end{array}$ \\
\hline Patients $(n=11)$ & $6 \mathrm{M}$ & $F 2 \cdot 83(0 \cdot 37)$ & $4 \cdot 86(0.51)$ & $4.9(0.49)$ \\
\hline Controls $(n=6)$ & $5 \mathrm{M}$. & $F 2.81(0.29)$ & $4 \cdot 28(0 \cdot 51)$ & $6 \cdot 34(1 \cdot 1)$ \\
\hline
\end{tabular}

of the probe. The position of the probe was confirmed at the beginning of each recording session by an abdominal $x$-ray and positioned so that the most proximal catheter was at Treitz level. The recording catheters were perfused with water by a low compliance pneumohydraulic perfusion system. ${ }^{\times}$Intraluminal pressures were detected by strain gauge transducers (Gould, Statham P 23) and were recorded by a Beckman $\mathrm{R} 511$ recorder.

Subjects were intubated nasally the day before the study. When the tube assembly was in position, the latex balloon was deflated and recordings were obtained for four hours in each subject after an overnight fast. In addition, all volunteers and seven patients were fed with a liquid meal (Polydiet TCM, $500 \mathrm{kcal}, 500 \mathrm{ml}$, protein $15 \%$, fat $30 \%$, carbohydrate $55 \%$ ) and recording continued for one hour.

ANALYSIS OF TRACINGS

Records were analysed visually by two observers who agreed on the identification of the different motor patterns. Used definitions were those reported previously. Phase 3 of the MMC required a burst of uninterrupted phasic waves at the frequency of slow waves and lasting at least three minutes." To be

Table 2 Number of $M M C$, propagated contractions $(P C)$, discrete clustered contractions (DCC) in 11 patients with ileoanal anastomosis: correlation with the results of pouch emptying study and bacterial overgrowth investigation

\begin{tabular}{|c|c|c|c|c|c|c|}
\hline \multirow[b]{2}{*}{$\begin{array}{l}\text { Reservoir } \\
\text { shape }\end{array}$} & \multicolumn{3}{|c|}{ Interdigestive study } & \multirow{2}{*}{$\frac{\begin{array}{l}\text { Post- } \\
\text { prandial }\end{array}}{\mathrm{DCC} / \mathrm{h}}$} & \multirow{2}{*}{$\begin{array}{l}\text { Bacteria } \\
\text { over- } \\
\text { growth }\end{array}$} & \multirow{2}{*}{$\begin{array}{l}\text { Pouch } \\
\text { lempty } \\
\text { ing } \\
(1 / \%)\end{array}$} \\
\hline & $\begin{array}{l}\text { Phase } \\
3 / 4 h\end{array}$ & $P C / 4 h$ & $D C C / 4 h$ & & & \\
\hline $\mathbf{J}$ & 2 & 9 & 7 & 2 & + & 98 \\
\hline $\mathbf{J}$ & 4 & 1 & 0 & ND & - & 70 \\
\hline $\mathbf{J}$ & 2 & 2 & 3 & 4 & - & 94 \\
\hline $\mathrm{J}$ & 2 & 1 & () & 8 & - & 10() \\
\hline $\mathbf{J}$ & 2 & 0 & 0 & 15 & - & $\varphi()$ \\
\hline $\mathrm{J}$ & 5 & () & () & 1 & - & 82 \\
\hline $\mathbf{J}$ & 1 & () & 10 & 5 & - & 85 \\
\hline $\mathrm{S}$ & 3 & 10 & 14 & ND & + & 0 \\
\hline $\mathrm{S}$ & 2 & 10 & () & ND & ND & () \\
\hline $\mathrm{S}$ & 4 & 1 & $x$ & ND & - & 42 \\
\hline $\mathrm{S}$ & 4 & 5 & 17 & 18 & - & 93 \\
\hline
\end{tabular}

ND: not done. 
categorised as propagated, a motor event needed to be recorded sequentially in three adjacent channels. Propagated contractions were single or double pressure waves that migrated through at least three recording sites at a fairly rapid rate of $2 \mathrm{~cm} / \mathrm{s}$. Discrete clustered contractions ${ }^{5}$ were rhythmic bursts of phasic contractions occurring at a rate of one/five sec, shorter than that of phase 3. Clustered contractions were preceded and followed by a period of absent motor activity. Statistical comparisons were by unpaired $t$ test.

\section{BACTERIAL OVERGROWTH}

Jejunal bacterial overgrowth was investigated in 10 patients. After an overnight fast, $50 \mathrm{~g}$ D-glucose were ingested with $250 \mathrm{ml}$ water and $\mathrm{H}_{2}$ breath test carried out at 30 minutes intervals for 240 minutes. Bacterial overgrowth was considered present if $\mathrm{H}_{2}$ excretion was $>5 \mathrm{ppm}$.

\section{Results}

CLINICAL RESULTS

The selection of patients for study provided a spectrum of clinical results varying from good to poor. Nine patients had normal continence and were able to defecate spontaneously. Two patients had bad results and had to intubate their pouch.

Stool frequency for the 11 patients ranged from three to 15 (mean $(\mathrm{SE})=6.35(1) / 24 \mathrm{~h})$. Stool weight per 24 hours ranged from 142 to $700 \mathrm{~g}=390$ (57) $\mathrm{g} / 24 \mathrm{~h})$.

The volume of saline retained during the continence test varied from 250 to $1500 \mathrm{ml}$ (mean (SE) $=928$ (92) $\mathrm{ml}$ ). The percentage of evacuation of their reservoir after the saline continence test varied from 0 to $100 \%($ mean $(\mathrm{SE})=68 \cdot 5(11) \%)$.

MIGRATING MOTOR COMPLEXES (MMC)

Characteristics of the MMC recorded from both groups of subjects are summarised in Table 1. No differences were found between patients and control subjects in the periodicity, duration, or velocity of phase 3 of the MMCs $(p>0 \cdot 05)$. All the volunteers and all the patients had at least one phase 3 during the fasting recording (range 1 to 5 for patients and 2 to 4 for normal subjects). The number of phase 3 was not different for $\mathbf{S}$ and $\mathbf{J}$ reservoir (Table 2) and was not different between patients studied at six and 12 months.

\section{PROPAGATED CONTRACTIONS}

In healthy volunteers, propagated contractions were an infrequent pattern in fasting (one contraction every 180 minutes) and were never seen postprandially.

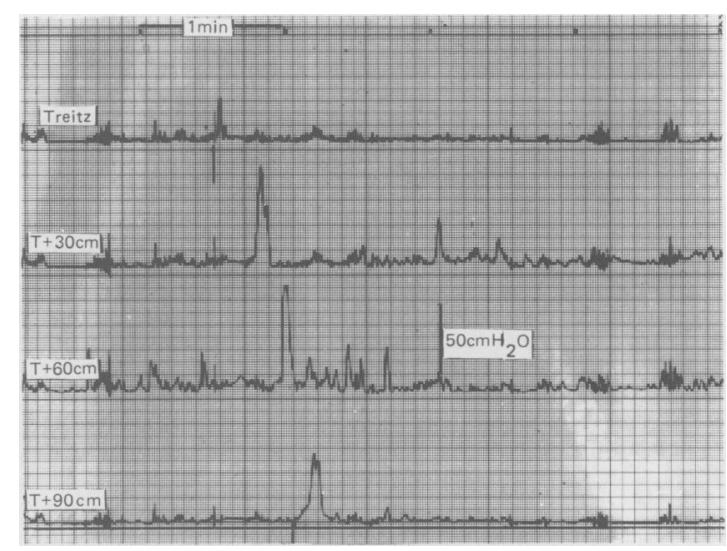

Fig. 1 Recording of jejunal motility in patients with ileoanal anastomosis: propagated contractions.

Among the patients (Table 2), four had numerous propagated contractions (respectively $5,10,10$, and 9 in 240 minutes) (Fig. 1) in fasting state $(2 \cdot 1 / \mathrm{h})$. Two of these had a bacterial overgrowth in the jejunum. In one patient, D-glucose breath test was not performed. Moreover, three of these four patients had an S shaped ileal reservoir; two needed intubation of the ileal pouch and had a percentage of evacuation of their pouch after the saline continence test equal to zero. Propagated contractions had a mean duration of $10 \cdot 5(0 \cdot 72) \mathrm{s}$ and a velocity of $2 \cdot 03(0 \cdot 14) \mathrm{cm} / \mathrm{s}$.

In the seven other patients propagated contractions were infrequent (Table 2). These patients had no bacterial overgrowth and the percentage of evacuation of their reservoir after a saline continence test was $80(7 \cdot 2) \%$ (range 42 to $100 \%$ ).

DISCRETE CLUSTERED CONTRACTIONS

In fasting state, discrete clustered contractions were seen more frequently in patients than in normal volunteers $(0 \cdot 17(0 \cdot 4) v 4 \cdot 8(2 \cdot 1) / \mathrm{h})$ but the difference was not significant as three patients had 10,14 , and 17 discrete clustered contractions during the four hours of recording (Table 2).

In the postprandial state discrete clustered contractions were never seen in normal volunteers but were found in all seven patients studied. The frequency of propagated discrete clustered contractions ranged (Table 2 ) from one to 18 per hour (mean $(\mathrm{SE})=7 \cdot 6(2 \cdot 5) / \mathrm{h})$. Duration, amplitude, velocity and distance of propagated waves are indicated in Table 3. Clinical data of patients are indicated in Table 4 . In these seven patients, the percentage of evacuation of the ileal pouch was $92(2 \cdot 5) \%$ suggesting there was no stool stasis in the patients' reservoir. Only one patient had a bacterial overgrowth in the jejunum. 


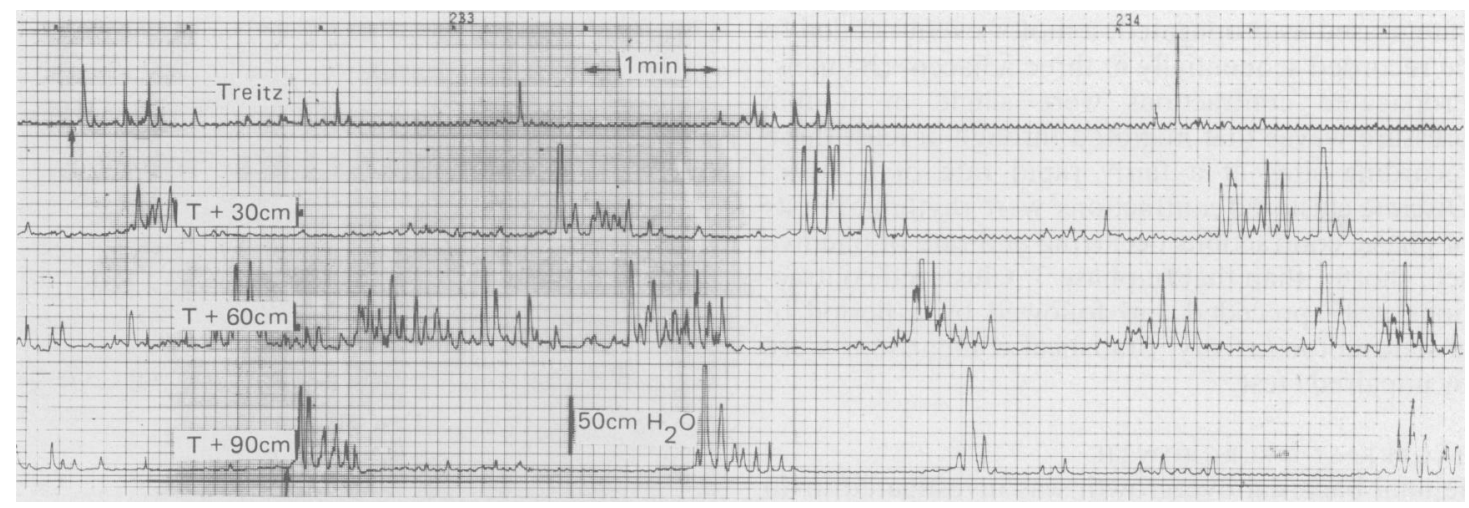

Fig. 2 Recording of jejunal motility in patients with ileoanal anastomosis after a meal: several discrete clustered contractions migrating distally are recorded.

\section{Discussion}

Fasting jejunal motility remained largely normal after proctocolectomy and ileal pouch anastomosis as previously described."' In our patients temporospatial organisation of the MMC, its duration and velocity were similar to those observed in healthy volunteers. Bacterial overgrowth was found in jejunum of only two patients. These two patients had normal occurrence of phase 3 despite bacterial overgrowth.

Four patients had an increased number of propagated contractions in the jejunum. This motility pattern or its electromyographic equivalent (the migrating action potential complex) has been described in man with secretory diarrhoea," ${ }^{\prime 2}$ in animals

Table 3 Number, duration, velocity of propagation and length of propagation of discrete clustered contractions (DCC) recorded in fed state in patients $(n=7)$ with ileal pouch anastomosis

\begin{tabular}{llll}
\hline $\begin{array}{l}D(c / h \\
(n)\end{array}$ & $\begin{array}{l}\text { Duration } \\
(\mathrm{sec})\end{array}$ & $\begin{array}{l}\text { Velocity of } \\
\text { propagation } \\
(\mathrm{cm} / \mathrm{s})\end{array}$ & $\begin{array}{l}\text { Length of } \\
\text { propagation } \\
(\mathrm{cm})\end{array}$ \\
\hline $7 \cdot 6(2.5)$ & $43.6(1.5)$ & $(0.76(0.06)$ & $72(3.4)$ \\
\hline
\end{tabular}

Table 4 Clinical data of patients with discrete clustered contractions in postprandial state $(n=7)$

\begin{tabular}{lc} 
Stool output $(\mathrm{g} / 24 \mathrm{~h})$ & $427(77)$ \\
Stool frequency/24 $\mathrm{h}$ & $5.26(0.71)$ \\
Maximum tolerable volume during the & $969(92) \mathrm{ml}$ \\
$\quad$ saline continence test & \\
Resting anal pressure & $51(8.5) \mathrm{cm} \mathrm{H}_{2} \mathrm{O}$ \\
$\%$ evacuation of the pouch & $92(2.5)$ \\
Jejunal bacterial overgrowth & $1 / 7(14 \%)$ \\
\hline
\end{tabular}

after exposure of the small intestine to diarrhoeagenic bacteria ${ }^{13}$ or to their enterotoxins or during bacterial overgrowth. Likewise the occurrence of propagated contractions could be the consequence of a bacterial overgrowth found in two patients. Two needed intubation of their ileal reservoir and in this condition small bowel overgrowth could be facilitated by stool stasis in the pouch. On the contrary, one patient, who normally emptied his pouch, had the highest stool output $(700)$ $\mathrm{g} /$ day) and faecal leakage during the night. This patient dramatically improved after a three weeks' course of antibiotics. Moreover propagated contractions are known to propel intestinal contents over long distances. Such motor patterns, originating in the proximal small intestine, could be responsible for the antibiotics curable high stool output observed in one patient. This motility pattern had been also found by Stryker et al ${ }^{\prime \prime}$ in three of eight patients in the distal jejunum and ileum. In this study, however, bacterial overgrowth and pouch emptying were not assessed. These propagated contractions have been shown to propel fluid through the canine or the human small intestine and could be the consequence of bacterial overgrowth or a response to storage of chyme in the pouch and perhaps distension of the small intestine. ${ }^{14}$

In the fasting period very few discrete clustered contractions were observed in the volunteers and patients. This contrasts with results from Stryker et $a l^{\text {tr }}$ but is in agreement with other studies. 'In the study by Summer et al, "clustered contractions occurred in normal subjects only during phase 2 with a mean frequency of $6 \cdot 2(3 \cdot 4) / \mathrm{h}$. The same contractile pattern was seen with a similar frequency in patients with mechanical obstruction of the small bowel.

In the postprandial period, numerous discrete clustered contractions were recorded in the seven 
studied patients and none in volunteers. Summer $e t$ $a l^{5}$ found the same motility pattern (frequency 8.9 $(6) / h)$ in the jejunum of patients with proximal or distal partial small intestine obstruction. The occurrence of a similar pattern in our patients suggests that ileoanal anastomosis could be responsible for a partial obstruction of the small intestine. Several mechanisms could be involved: inefficiency of evacuation of the ileal pouch can be ruled out as the percentage of evacuation of the pouch in the seven patients studied postprandially was equal to $92 \%$. Bacterial overgrowth was found in only one case. Lastly, the anal sphincter is closed at most times and thus, could cause obstruction as in normal conditions ileocaecal value represents only a discrete zone of tonic activity. ${ }^{15}$ In a previous work ${ }^{2}$ we have shown that the volume of ileal reservoirs increased by $250 \%$ by six months after the closure of the loop ileostomy. Such an increase could also be because of a functional partial obstruction related to the recovered function of the anal sphincters. Our results differed from those of Stryker et al ${ }^{\prime \prime \prime}$ who did not find a similar motility pattern in the early postprandial period. Such a discrepancy could be explained by the difference in experimental designs. The site of recording was upper jejunum in our study while Stryker et al ${ }^{10}$ recorded distal jejunum and ileum. A liquid meal was used in our study instead of a normal meal as in the Stryker study. ${ }^{10}$ As gastric emptying of liquids is faster than emptying of solids, this difference could be important because high duodenal or jejunal flow has been shown to facilitate the appearance of discrete clustered contractions. ${ }^{16}$ On the other hand, different test meals could stimulate the intestine to a different extent ${ }^{17}$ and may obscure or facilitate the appearance of specific motility patterns as discrete clustered contractions.

In conclusion MMC organisation is normal after ileoanal anastomosis and a bacterial overgrowth is a rare event. In the postprandial state, the occurrence of discrete clustered contractions suggest that ilcoanal anastomosis is responsible for a partial obstruction of the small intestine.

\section{References}

1 Metcalf A, Dozois R, Kelly K, Wolff B. Ileal 'J' pouch anal anastomosis: clinical outcome. Ann Surg 1985; 202: $735-9$.

2 Chaussade S, Verduron A, Hautefeuille M, Valleur P. Hautefeuille P. Couturier D. Proctocolectomy, ileal pouch anastomosis, without conservation of a rectal muscular cuff: clinical and physiological results 6 months after closure of the covering loop ileostomy [Abstract]. Gastroenterology 1987: 92: 1342.

3 Stryker S, Phillips SF, Dozois RR, Beart RW, Kelly K. Anal and neorectal function after ileal pouch anal anastomosis. Ann Surg 1986; 203: 5.5-61.

4 Nicholls RJ, Pezim ME. Restorative proctocolectomy with ileal reservoir for ulcerative colitis and familial adenomatous polyposis: a comparison of three reservoirs designs. Br J Surg 1985; 72: 470)-4.

5 Summers W, Anuras S, Green J. Jejunal manometry patterns in health, partial obstruction, and pseudoobstruction. Gastroenterology 1983; 85: 129()-300.

6 O'Connel PR, Rankin DR, Weiland LH, Kelly KA. Enteric bacteriology, absorption, morphology and emptying after ileal pouch anastomosis. Br J Surg 1985; 73: 909-14.

7 Haynes WG, Read NW. Ano - rectal activity in man during rectal infusion of saline: a dynamic assessment of the anal continence mechanism. J Physiol 1982: 330: 4556.

8 Arndorfer RC, Steff JJ, Dodds WJ. Improved infusion system for intraluminal esophageal manometry. Gastroenterology 1977; 73: 23-7.

9 Vantrappen G, Janssens J, Hellemans J, Ghoos Y. The interdigestive motor complex of normal subjects and patients with bacterial overgrowth of the small intestine. J Clin Invest 1977; 59: 1158-66.

10 Stryker SJ, Borody T, Phillips SF, Kelly K, Dozois R, Beart RW. Motility of the small intestine after proctocolectomy and ileal pouch-anastomosis. Ann Surg 1984; 201: $351-6$.

11 Coremans G, Janssens J, Vantrappen G, Chaussade S, Ceccatelli $P$. Migrating action potential complexes in a patient with secretory diarrhea. Dig Dis Sci 1987; 32: $1201-6$

12 Kellow J, Phillips SF, Miller L, Osterholm M, MacDonald K. Abnormalitics of motility and absorbtion in an outbreak of chronic diarrhea [Abstract]. Gastroenterology 1985; 88: 1442.

13 Burns TW, Mathias JR, Carlson G, Martin J, Formal S, Shicld RP. Effect of toxigenic escherichia coli on myoelectrical activity of the small intestine. Am J Physiol 1978; 235: 311-25.

14 Sjogren RW, Wardlow M, Charles LG. Stimulation of action potential complexes by fluid distension of rabbit small intestine - evidence that migrating action potential complexes are a non specific myoelectric response. In: Roman C, ed. Gastrointestinal motility. Lancaster: MTP Press, 1984: 287-96.

15 Nasmyth DG, Williams NS. Pressure characteristics of the human ileocecal region - a key to its function. Gastroenterology 1985; 89: 345-51.

16 Fleckenstein P. Bueno L, Fioramonti J, Ruckebuusch Y. Minute rhythm of electrical spike bursts of the small intestine in different species. Am J Physiol 1982; 242: 654-9.

17 Schemann M. Ehrlein HJ. Postprandial patterns of canine jejunal motility and transit of luminal content. Gastroenterology 1986; 90: 991-1000). 